\title{
The development of Business English courses using online technology to address the emerging needs in the Cypriot context
}

\section{Victoria Kalogerou ${ }^{\text {a }}$}

${ }^{a}$ University of Nicosia, Nicosia, Cyprus, Kalogerou.v@unic.ac.cy

\begin{abstract}
The global financial crisis, the implosion of the local economy in Cyprus, as well as European and global trends pertaining to the modernization of Higher Education (HE), have urged educational administrators, departments and faculty members to rethink the mode of delivery of their traditional faceto-face courses and redesign them with the support of electronic online platforms, Moodle is a case in point, in blended learning mode or entirely in Distance Learning mode and thus increase student enrollement and satisfaction as well as minimize costs for their respective institutions. Towards these goals the utilization of the Moodle Learning Management System has been in a gradual manner widely accepted and has been increasingly gaining popularity at the European as well as at the global level in helping converting traditional courses into online ones apart from introducing options for blended learning. In this paper, I present initially the rationale behind the need to redesign and deliver a Bachelor degree in Business Administration in Distance learning mode in the first language of the majority of the enrolled students, Greek. Then I move on to describe the steps taken in order to offer for the first time the course BADM231 (Business Communications) in Greek using the Moodle Learning Platform to convert the traditionally taught course while I also present and discuss the associated challenges prior to launcing the course in entirely Distance Learning Mode in Spring 2018. Finally I briefly report on the solutions saught and their implementation and I close by setting the goals for the future.
\end{abstract}

Keywords: Distance Learning, Electronic Learning Platforms, $21^{\text {st }}$ century learning, Effective teaching and learning, Language in the Workplace 


\section{Introduction}

Learning through the internet has been increasing gaining popularity in the field of HE in Europe (Rys and Chadaj, 2014) and beyond (Habiba and Crowdhury, 2012), while at the same time the demand for offering courses in the mother tongue - particularly in multilingual environments - has intensified in many countries (Cf. Bamgbose, 2004; Jayaram, 1993). The insessant competition in securing student numbers intact in times of economic resession has led educational management in institutions, particularly in the private sector, to redesign courses traditionally taught in the island's widely spoken oficial lanaguge, Greek.

This in turn has increased the demand for lecturers fluent in the mother tongue, to redesign, administer and deliver courses entirely in Greek. This process has been slow, as the change did not only imply translating the slides from one language to the other; it has led to a number of associated challenges, including finding appropriate bibliography and relevant resources in the target language.

In the sections that follow, I explain in detail the rationale as well as the steps taken in order to convert the course BADM231 (Business Communications) in Greek as BADM231DG

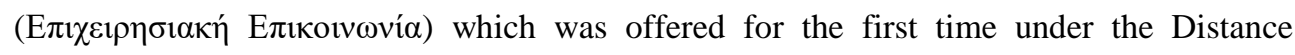
Learning Programme of the University of Nicosia, in Spring semester 2018 under the

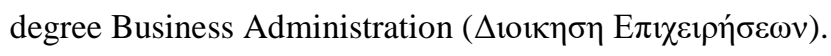

\section{Educational Needs in the Cypriot context}

\subsection{Background}

Cypriot economy relies mainly on two major sources, tourism and services. Following the haircut in 2013, when many companies imploded, educational administration in the private sector in particular has been involved in a process of making strategic decisions to safeguard interests and income while assisting to the boosting of the overall economy. The University of Nicosia, loyal to its contribution to society, has recorded the recurrent need to offer courses in Greek, to its local, i.e.: face-to-face audiences but also abroad, mainly in Greece and in countries where there is a strong Greek presence, i.e.: Canada, Australia and the US among others. 
Further to this, the haircut of the funds in the two main banks on the island, the merge of these two banks and the inclusion of the island to the EU emergency support mechanism, have had a number of overt and covert consequences for the Cypriot market. Instantaneously, many companies' payrolls could not run as funds over 100000 euros were subjected to a haircut. As a result, many people were made reduntant immediately or sucked depending on their contractual agreements. At the same time, many individuals saw a lifetime's savings turn to ashes. Many had to seek psychological support in ordet to deal with the losses. The vast majority of employees, both in the public and private sector had to sacrifice parts of their salaries to contribute to the improvement of the country's finances: a percentage had to be paid to the government in the form of "special contribution". Others had to accept greater deductions in their salaries in order to avoid layoffs in personnel and secure the number of posts within companies.

Loan agreements were also on a certain extent in jeopardy as households found themselves overnight uanble to pay off mortgage agreements and/or other loans. Numerous loan agreements were renegotiated, others became cases for mediation following directives from the Financial Ombudsman while some were sent off to court. All the aforementioned changes, have had an impact on the overall economy. Private universities, whose primary income comes from student tuition suffered great losses as many students could not afford to pay their fees. Several easements were offered to students while at the same time, management urged departments to come up with alternatives to respond to the emerging needs and increase income.

\section{The significance of e-learning as a means to boost education and income}

According to Sloman (2001), e-learning allows the delivery of information, communication, education and training with the use of online tools. The flexibility of electronically-based approaches allows for teaching, learning and training to be conducted anywhere, anytime. As such, it leads to major savings in operational costs, including travel and accommodation expenses, facility maintainance and utility costs. Learning can occur syncronously or asynchronously allowing dispersed users to access online learning tools from various locations while remaining committed to work or personal obligations ( $\mathrm{Cf}$ Matijašević-Obradović1 et al 2017).

With the implementation of e-learning tools most activities are centrally monitored and recorded allowing participants to watch them either at the same time or whenever they so wish. Possibly the most popular learning platform in Higher Education is Moodle which provides a free, open-source platform for distance learning. The platform may be used as a 
primary tool for teaching and learning, for courses that are offered entirely in Distance Learning mode for example, but also as an additional tool to complement learning offered in the traditional face-to-face mode. The software allows for easy creation, management, delivery and modification of courses, it is as safe as other software used in other organisations in the field of Higher Education, but also beyond it (Kovačević and Gavrilović, 2011) and it is increasingly growing in popularity in the global scale (Milićević and Milić, 2014). The Moodle educational platform can be accessed by different users such as teachers - who create and regulate the content, students - who can view the uploaded content and submit coursework, assignemnts and access forums for the courses they are registered to, and finally guests - users who are not logged on to the system with a username and password, but may view some courses in full, or limited content in some.

This way, the platform allows for access to students and lecturers in a password protected format, in a cost effective manner for the provide - UNic is a case in point - while also in an indirect manner provides information for the courses to the public, functioning as a marketing tool for prospective students. Through the platform, people from the industry may also enroll to particular courses/modules of interest without formally registering to a certain degree, promoting this way lifelong learning.

Having briefly presented the advantages of using the online platform Moodle I move on to present how my course BADM231 has been adjusted in such a way to facilitate students who wish to improve their communication in Greek at the workplace.

\section{Converting BADM231 (Business Communications) face-to-face to

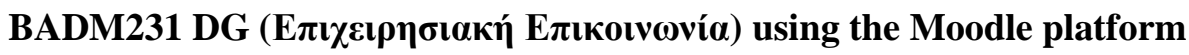 for Distance Learning.}

I have been offering the course BADM231 (Business Communications) for more than a decade in English in face-to-face mode, prior to being asked to offer it in Greek for the needs of a new degree offered entirely online in Distance learning mode in collaboration with the School of Business, namely BBA (Bachelors in Business Administration). Till that date, the course was offered only in face-to-face mode in English, while there was online material available through the password protected platform accessed by UNic full-time and part-time faculty as well as students registered for the particular course namely the Intranet.

The textbook used for the course has been "Business Communications Today" by Bovee and Thill first edition in 2000), which apart from the theoretical materials, included exercises at the end of each chapter and has gradually included a lot of online materiasl 
accessible through the publisher's platform. For the needs of the particular course I had created my own slides, which were used in class for the course's delivery and were also available online through the Student Intranet to the students registered in my sections.

Changing the language of delivery led in turn to a number of changes in the course which were necessary not only to deliver the materials in an effective manner but also to ensure the same standards of quality with the face-to-face mode. For this reason, the changes in the course occurred in a series of steps presented in this section. The course had to be created on the Moodle platform in a way that is familiar to Moodle users (See figure 1).

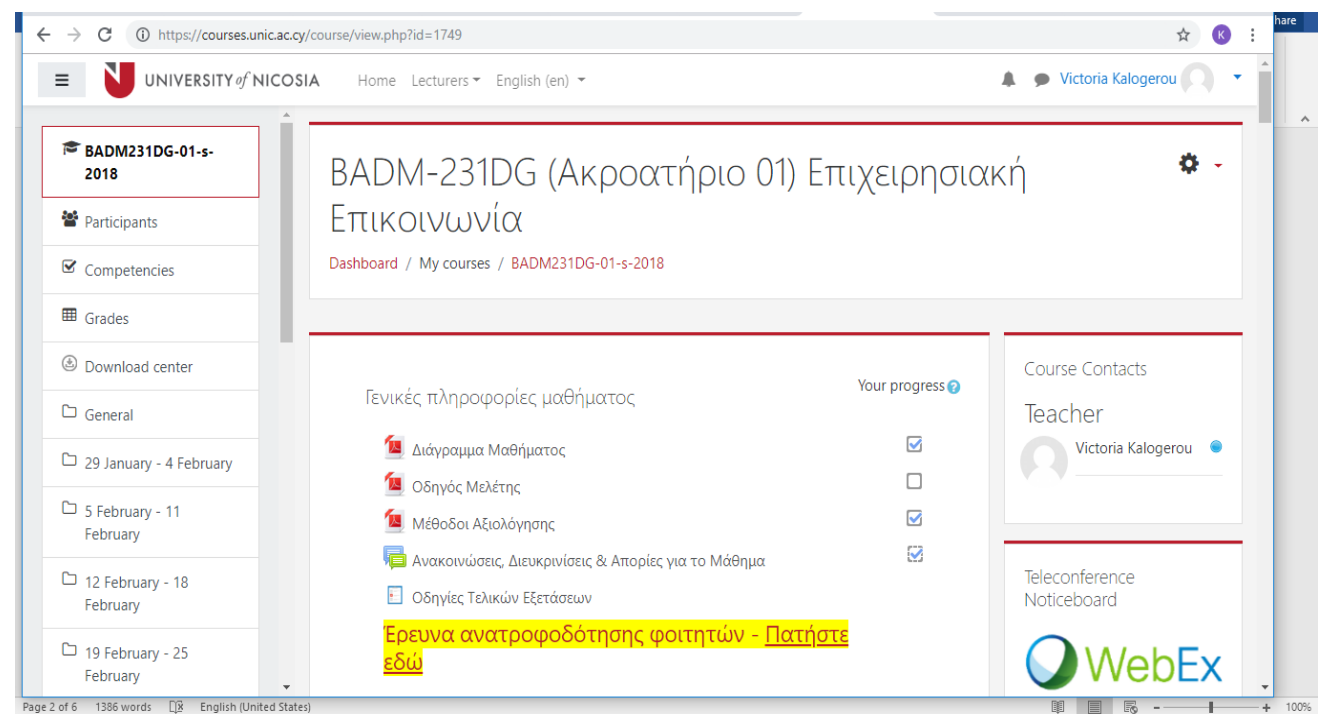

Fig. 1 Introduction to the course

Once this was done the materials, including slides, examples, exercises and assessment tools had to be translated in Greek. This was associated with a number of challenges as it had to be ensured that the translated terms corresponded correctly to their equivalents used at the workplace in Greece and do not sound strange, foreign or are associated with negative connotations in the target language. This required additional research and discussions with experts in the field mainly in Greece where the standard Modern Greek originates in.

At the same time, while it is common practice for courses to be delivered in the target language and for terminology to be maintained in the language of origin as well as maintaing the same book, usually the version used for the american audience, I was struck 
The development of Business English courses using online technology to address the emerging needs in the Cypriot context

by how weird this seemed in a course offered entirely in DL mode. For this reason, I searched extensively for original sources (i.e., emails, memos and formal letters, etc.) in Greek thus creating a brand new database more useful for students who enrolled in this course and mode. These sources were first checked and readjusted to abide by the General Data Protection Regulation (GDPR) enacted in Cyprus in May 2018 and then they were converted to PDF format and uploaded in the appropriate sections on the Moodle platform as shown in figure 2.

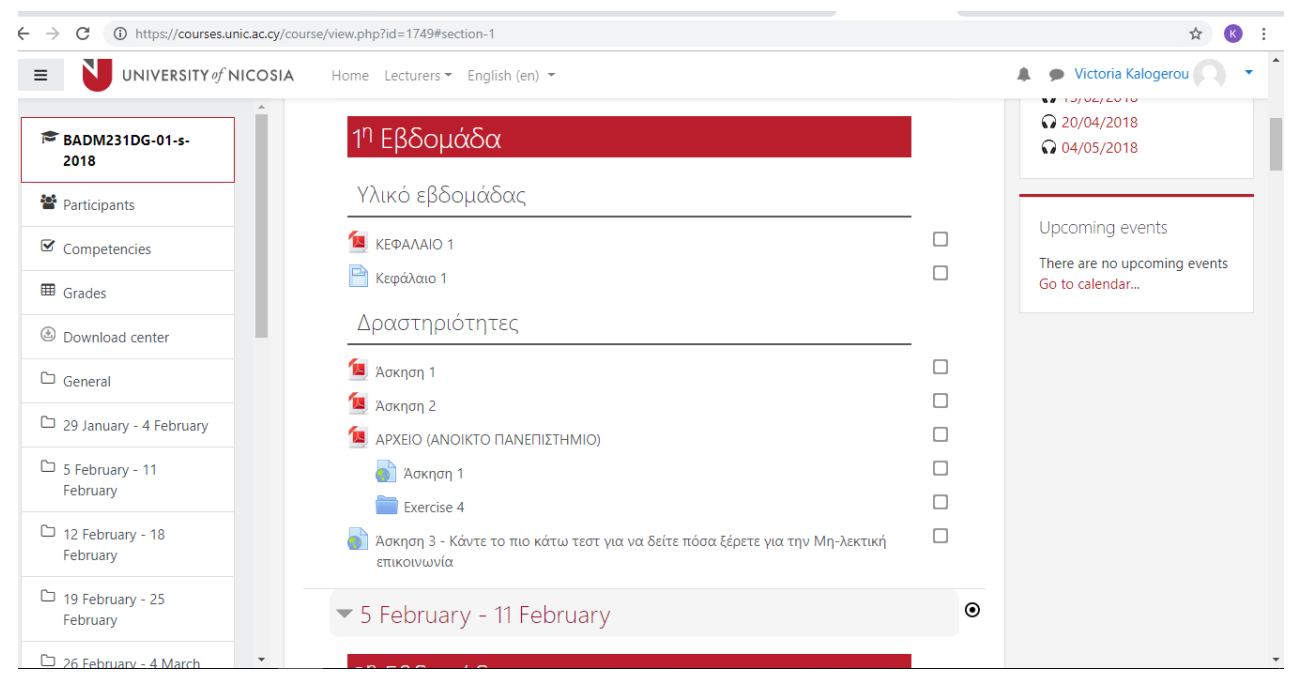

Fig. 2 Original sources used in the appropriate sections of the course.

At the same time, forums and discussions had to be held in the target language and questions and answers had to be entirely in Greek to ensure the uniformity of the course, but also to enable all participants to follow them in spite of their competence in English language as shown in figure 3. 


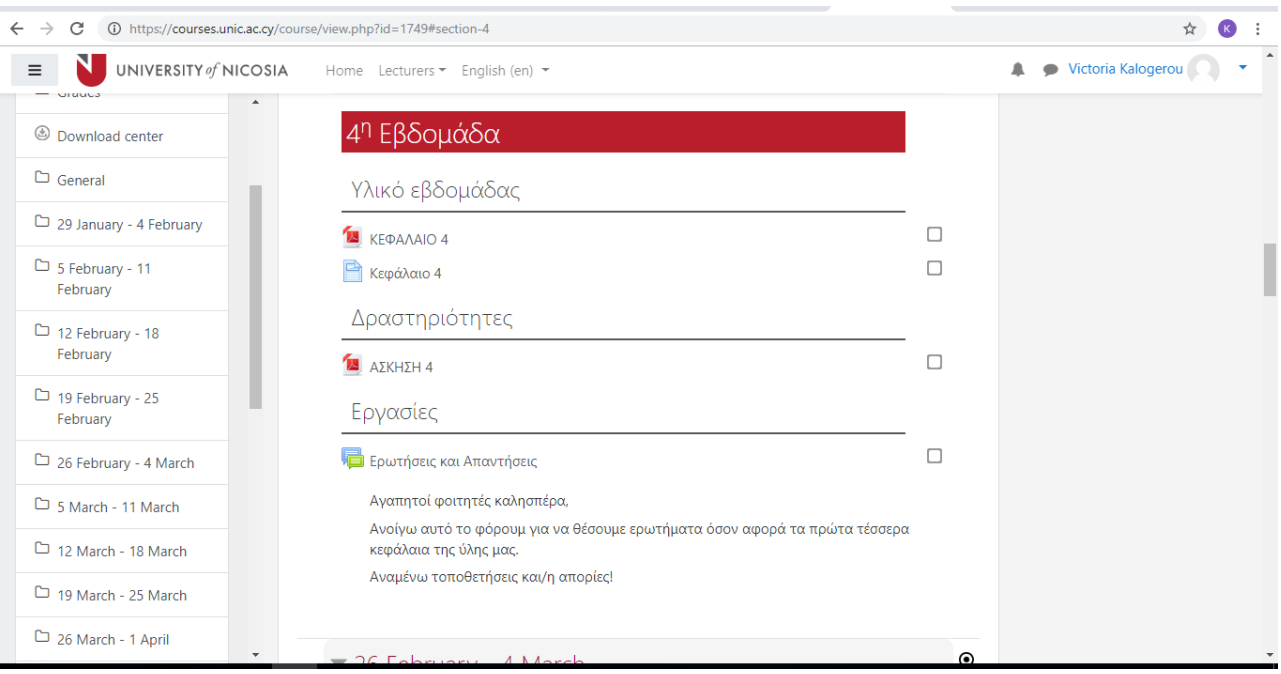

Fig. 3 Forums and discussions

Finally assessement had to be adjusted to Greek in order to enable students tackle the tasks helping them thus improve their performance in the final face-to-face examination in the examination centres which counts for $60 \%$ of their final grade. Offering assessement tools via the platform also helps in promoting autonomous learning as shown in figure 4 .

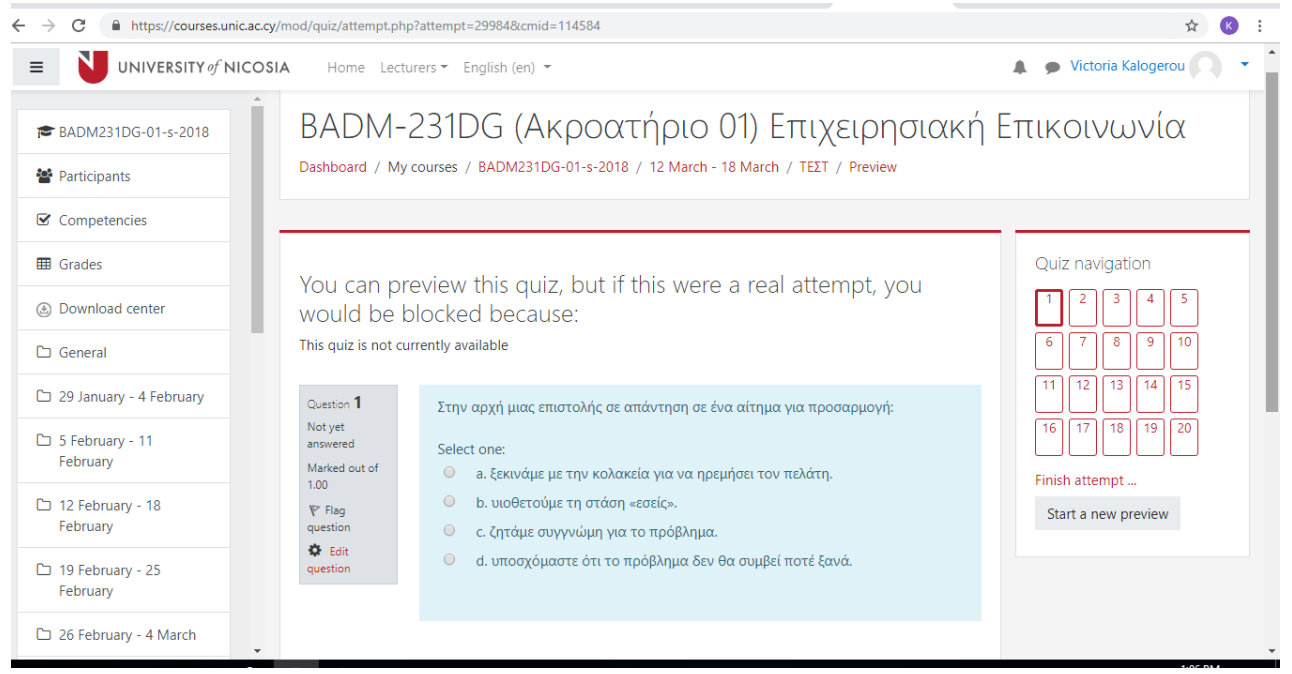

Fig 4. MCQs and online assessment

Finally, upon completion of the course students could evaluate the course and the lecturer as in the face-to-face courses as shown in figure 1 (highlighted). As with the face-to-face 
courses changes/alterations/modifications occurred to the course based on the immediate feedback from students following the WebEx sessions but also informal feedback through telephone conversations and emails. In addition to these, the formal evaluation of the students also added to the changes that needed to occur in order for the course to be offered in a more effective manner.

\section{Conclusion}

In this paper, initially the rationale behind the conversion of courses leading to a Bachelor degree in Business Administration in Distance learning mode in the Greek language are presented. Then, the steps taken towards the conversion of the traditional face-to-face mode of delivery for my course BADM231 (Business Communicaions) to the online delivery using the Moodle Learning Platform are described. Further to offering a degree in Distance Learning mode to those who wish to improve their communication in Greek at the workplace as this is the main language of communication or to students who wish to study part time or from a remote location, this conversion has also replaced the prior decentralized organizational structure of the courses leading to a BBA degree which consisted of various and sometimes incompatible modules. Uploading courses on the Moodle platform made it easier to operate, maintain and update courses by one unit, i.e. a dedicated Distance Learning Support Centre at UNic, catering not only to the faculty's and students' needs but also abiding by the internal and external standards of quality and compliance. Offering the course in Greek by using the online platform has also demonstrated the need for offering Business communications in Greek to those who handle almost entirely their day-to-day communication at the workplace using the Greek language. Future work shall focus on improving the delivery and materials for the course as well as researching whether a face-to-face delivery in the form of a module or a short course might be of interest to the organization.

\section{Acknowledgments}

Many thanks to Mr. Alexis Kofterides (CEO in CandyJar Boutique Advertising) who helped in using the most appropriate terms in the Greek language, Dr. Despo Ktoridou (Head of the Department of Management and MIS) for including me in the Distance Learning Initiative and Ms. Cynthia Efremoglou (LMS Programme Management Senior Officer) for her constant support in developing and offering this course. 


\section{References}

Bamgbose, A. (2004) Language of Instruction Policy and Practice in Africa Paris: UNESCO, 2004. http://www.unesco.org/education/languages_2004/languageinstruction_africa.pdf.

Habiba, U. and Chowdhury, S. (2012) Use of Electronic Resources and its impact: A study of Dhaka University Library Users in the Eastern Librarian, Volume 23 (1) ISSN: 1021-3643, pp. 74-90,

Jayaram, N. (1993). The Language Question in Higher Education: Trends and Issues. Higher Education, 26(1), 93-114. Retrieved from http://www.jstor.org/stable/3447879

Kostić Kovačević, I. and Gavrilović, J. (2011) Incorporating educational software for dynamic mathematics in the system for distance learning", in: Infoteh - Jahorina - Ref. E-V-7, Vol. 10, East Sarajevo: Faculty of Electrical Engineering, pp. 780-783, 2011.

Matijašević-Obradović, J.; Dragojlović, J. and Babović, S. (2017) The importance of Distance Learning and the use of Moodle Educational platform in Education in the International Scientific Conference on Information Technology and Data Related Research, Sinteza, pp. 236-241.

Rys, D. and Chadaj, N. (2014) Electronic sources in libraries of Polish technical universities; yesterday and today in Library and Information Research, Vol. 38, no. 118 2014, pp.1-13.

Sloman, M. (2001) The e-learning revolution from propositions to actions, Charted Institute of Personnel and Development, McGraw-Hill Education: Europe. 